Abstract

\title{
Impact of Insect Larvae on Meat Quality ${ }^{\dagger}$
}

\section{Louwrens C. Hoffman}

Queensland Alliance for Agriculture and Food Innovation (QAAFI), The University of Queensland, St Lucia, Brisbane, QLD 4072, Australia; louwrens.hoffman@uq.edu.au

+ Presented at the third International Tropical Agriculture Conference (TROPAG 2019), Brisbane, Australia, 11-13 November 2019.

Published: 8 April 2020

\begin{abstract}
The use of the black soldier fly (BSF: Hermetia illucens) as a means of upstreaming waste has enjoyed increasing research the past few years. One of the uses of the resultant larvae is as animal feed, with particular success achieved when fed to mono-gastric animals. Most of the research has been on the use of BSF as feed in poultry and fish species. In poultry, larvae were produced on abattoir waste, kitchen waste or faecal matter (human and animal manure). The insects were grown until harvest as larvae, pre-pupae or pupae. The post-harvest processing included freezing, drying and/or milling. Where the poultry were fed Iso-nitrogenous/Iso-energetic diets containing various proportions of BSF, no differences in production performance or carcass yields (breast-, thigh-yields) were found. As pertaining to meat quality, no differences for initial $\mathrm{pH}$ or ultimate $\mathrm{pH}$ of the meat were noted. Differences for breast colour measurements were found; larvae fed chicken breast meat was generally lighter and redder whilst results on the breasts' water binding capacity was inconclusive. For sensory attributes, no differences were observed except for juiciness and sustained juiciness. Sometimes a metallic flavour was noted, particularly on larvae fed on abattoir wastes. Manipulating the larvae's diet as a strategy to change the chemical composition of the poultry has focused on attempts to change the fatty acid profiles and yielded mixed results; irrespective of the fatty acid profile, the fat of BSF larvae contains large amounts of lauric acid; known to have profound antiviral and antibacterial activity.
\end{abstract}

Keywords: agricultural wastes; insect protein; BSF; chicken; broiler meat; poultry

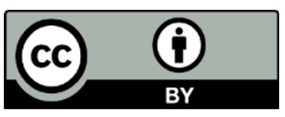

(C) 2020 by the authors. Licensee MDPI, Basel, Switzerland. This article is an open access article distributed under the terms and conditions of the Creative Commons Attribution (CC BY) license (http://creativecommons.org/licenses/by/4.0/). 